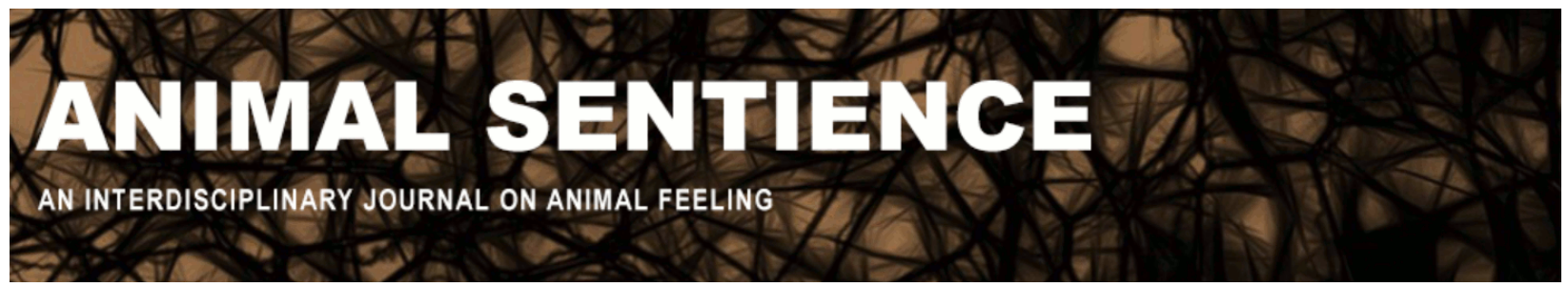

Broom, Donald M. (2016) Fish brains and behaviour indicate capacity for feeling pain. Animal Sentience 3(4)

DOI: $10.51291 / 2377-7478.1031$

Date of submission: 2015-10-01

Date of acceptance: 2015-12-11

(c)

This article has appeared in the journal Animal

Sentience, a peer-reviewed journal on animal

cognition and feeling. It has been made open access,

free for all, by WellBeing International and deposited

in the WBI Studies Repository. For more information,

please contact

wbisr-info@wellbeingintl.org.

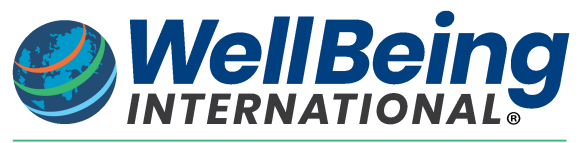

SOLUTIONS FOR PEOPLE, ANIMALS AND ENVIRONMENT 


\title{
Fish brains and behaviour indicate capacity for feeling pain
}

\author{
Commentary on Key on Fish Pain
}

\author{
Donald M. Broom \\ Centre for Anthrozoology and Animal Welfare \\ University of Cambridge
}

\begin{abstract}
Studies of behaviour are of major importance in understanding human pain and pain in other animals such as fish. Almost all of the characteristics of the mammalian pain system are also described for fish. Emotions, feelings and learning from these are controlled in the fish brain in areas anatomically different but functionally very similar to those in mammals. The evidence of pain and fear system function in fish is so similar to that in humans and other mammals that it is logical to conclude that fish feel fear and pain. Fish are sentient beings.
\end{abstract}

Donald M. Broom dmb16@cam.ac.uk, Emeritus Professor of Animal Welfare, Cambridge University, has developed concepts and methods of scientific assessment of animal welfare. http://www.animal-welfareindicators.net/site/index.php/professor-donald-m-broom

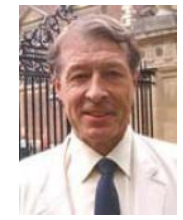

Key (2016) is scornful about evidence from studies of fish behaviour indicating that fish are aware and feel pain but presents a thorough explanation of the pain system in the human brain and concludes that fish could not feel pain, or have any other feelings, as they do not have the brain structures that allow pain and other feelings in humans. Section 2 of his paper emphasises "the cortical origins of human pain" and states that "structure determines function," explaining the functions of the five layers of the human cortex. He also argues that there is "no evidence for the emergence of novel pain regions in the fish nervous system" because "the circuitry is inadequate" and "feedforward pathways" are simple explanations for responses apparently parallel with what occurs in the brain when something is felt in humans.

Key perpetuates the distinction between nociception and pain, which is a relic of attempts to emphasise differences between humans and other animals or between "higher" and "lower" animals. Where pain is an aversive sensation and feeling associated with actual or potential tissue damage (Broom, 2001, modified after International Association for the Study of Pain, Iggo, 1984), the use of the term nociception, which separates one part of the pain system from other parts, should be discontinued. The system should be considered as a whole (Wall, 1992; Broom, 2001, 2014).

The selective advantage of being able to feel and learn from pain, fear and other feelings has been argued for by Broom (1998, 2001, 2014), Dawkins (2012), and Sneddon et al. (2014). Active animals with sophisticated behaviour, such as all vertebrates and certain invertebrates, need a certain level of pain and other feelings in order to respond effectively to their environment and survive. Hence pain and fear systems are phylogenetically old and very unlikely to have suddenly appeared in mammals or in humans. 
Key issues in any discussion of fish welfare are whether fish are aware of what is happening around them, whether they are capable of cognitive processing and whether they can have feelings such as pain (Chandroo et al., 2004; Broom 2007, 2014, 2015; Broom and Fraser, 2015). Our best evidence for pain and other feelings in humans is derived from observations of behaviour. Evidence from human reporting is less reliable and the anatomical evidence is of little use without observations of behaviour and physiology.

There has been evidence for many years that some fish must have mental representations of their environment in order to be able to navigate (Reese, 1989; Rodriguez et al., 1994), learn spatial relationships (Odling-Smee and Braithwaite, 2003), use information about sequences of spatial information (Burt de Perera, 2004), recognize social companions (Swaney et al., 2001), and avoid for some months or years places where they have previously encountered a predator (Czanyi and Doka, 1993) or were caught on a hook (Beukema, 1970). Recent learning studies (Salwiczek et al., 2012; Pepperberg and Hartsfield, 2014) showed that in a complex learning task in which they have to learn to discriminate reliable from ephemeral food sources, cleaner-wrasse fish (as well as parrots) perform better than chimpanzees, orangutans or capuchin monkeys. It is likely that many of these fish abilities are associated with some degree of feeling. The timing of events can be integrated to allow fish to produce appropriate avoidance responses (Portavella et al., 2004; Yue et al., 2004). It is difficult to explain the results of their studies without assuming that the fish feel fear.

Evidence for pain in fish is reviewed by Braithwaite (2010) and Sneddon et al. (2014). Fish nociceptors are very similar to those of mammals and, of the 18 criteria for pain perception listed by Sneddon et al. (2014), 17 are common to fish and mammals; only relief learning has not yet been demonstrated for fish. For example, in the rainbow trout, Onchorhynchus mykiss, anatomical and electrophysiological investigation of the nociceptors connected to the trigeminal nerve has revealed that these fish have two types of nociceptor, A-delta and $c$ fibres (Sneddon, 2002; Sneddon et al., 2003a). The transmitter substance P, and the analgesic opioid enkephalins and $\beta$-endorphin, which act as endogenous analgesics in mammals, are present in fish (Rodriguez-Moldes et al., 1993; Zaccone et al., 1994; Balm and Pottinger, 1995) and the behavioural responses of goldfish to analgesics are the same as in rats (Ehrensing et al., 1982). When Sneddon et al. (2003b) administered weak acetic acid solution or bee venom to the mouth of a trout, the fish rested on the substratum, rocked from side to side and rubbed their snouts on solid surfaces. These behaviours stopped when the analgesic morphine was given.

In fish the parts of the brain used during fear and pain responses are not anatomically the same (Broglio et al., 2003) as in mammals, but the function is very similar. Different groups of fish may use different parts of their brains to show fear and pain responses and learn from them. Recent information about fear and pain behaviour (Portavella et al., 2004) shows that fish have in their brains areas with functions that closely parallel those of the amygdala and hippocampus in mammals. These are the brain areas in mammals that process emotion, feeling and learning from emotions. In some fish, the medial and lateral telencephalic pallium process emotion and learning. Kawakami and colleagues have shown that zebrafish, learning from a fear situation, have brain activity in the habenula and other areas and that transgenic fish that lack such areas, and normal fish treated with a neurotoxin that targets 
such areas, cannot respond to and learn from fear responses. Asakawa et al. (2008) describe the production of such effects in the transgenic zebrafish, Muto et al. (2013) demonstrate visualization of neuronal activity in the optic tectum of larval zebrafish during active behaviour, and Agetsuma et al. (2010) give evidence for the habenula being critical for feardependent learning in zebrafish. Further work links the imaging and brain area deletion evidence for the functions (Kawakami, personal communication).

Fish do not have an amygdala and hippocampus that is anatomically homologous to those of humans, but they have analogous brain areas whose function is to control and learn from emotional responses. Key argues that "neither the medial pallium nor the whole pallium is required for escape behaviours from electric shock stimuli in fish" and that ablation of the midbrain optic tectum in goldfish does not affect escape responses. However, such escape may be controllable by a different brain area. Key's argument about the effects of lesions on pallial sub-regions in fish does not show that fish do not feel pain. The findings of Portavella, Kawakami and others strongly support the existence and functioning of systems for emotional response to and learning from fear and pain in fish.

I agree with Key that "pain involves conscious neural processing" but conclude that the evidence of pain system function in fish is so similar to that in humans and other mammals, it is not logical to deduce that fish cannot feel pain. Fish are sentient beings and public attitudes to them are gradually changing as scientific evidence for their capabilities accumulates (Broom, 2014). 


\section{References}

Agetsuma, M., Aizawa, H., Aoki, T., Nakayama, R., Takahoko, M., Goto, M., Sassa, T. Kawakami, K. and Okamoto, $\mathrm{H}$. (2010). The habenula is crucial for experience-dependent modification of fear responses in zebrafish. Nature Neuroscience, 13, 1354-1356.

Asakawa, K., Suster, M.L., Mizusawa, K., Nagayoshi, S., Kotani, T., Urasaki, A., Kishimoto, Y., Hibi, M. and Kawakami, K. (2008). Genetic dissection of neural circuits by Tol2 transposon-mediated Gal4 gene and enhancer trapping in zebrafish. Proceedings of the National Academy of Sciences, 105, 1255-1260.

Balm, P.H.M. and Pottinger, T.G. (1995). Corticotrope and melanotrope POMC-derived peptides in relation to interrenal function during stress in rainbow trout (Oncorhynchus mykiss). General Comparative Endocrinology 98, 279-288.

Beukema, J.J. (1970). Angling experiments with carp: decreased catchability through one trial learning. Netherlands Journal of Zoology, 20, 81-92.

Braithwaite, V. (2010). Do fish feel pain?. Oxford: Oxford University Press.

Broglio, C., Rodriguez, F. and Salas, C. (2003). Spacial cognition and its neural basis in teolost fishes. Fish and Fisheries, 4, 247-255.

Broom, D.M. (1998). Welfare, stress and the evolution of feelings. Advances in the Study Behaviour, 27, 371-403.

Broom, D.M. (2001). Evolution of pain. In E.J.L. Soulsby \& D. Morton (Eds.), Pain: Its nature and management in man and animals. Royal Society of Medicine International Congress and Symposium Series, 246, 17-25.

Broom, D.M. (2007). Cognitive ability and sentience: which aquatic animals should be protected? Diseases of Aquatic Organisms, 75, 99-108.

Broom, D.M. (2014). Sentience and Animal Welfare (p. 200). Wallingford: CABI.

Broom, D.M. (2015). Sentience and pain in relation to animal welfare. Proceedings of XVII International Congress on Animal Hygiene, 3-7. Košice, Slovakia: International Society for Animal Hygiene.

Broom, D.M. and Fraser, A.F. (2015). Domestic Animal Behaviour and Welfare (5th ed., p. 472). Wallingford: $C A B I$.

Burt de Perera, T. (2004). Fish can encode order in their spatial map. Proceedings of the Royal Society, London B 271, 2131-2134.

Chandroo, K.P., Duncan, I.J.H. and Moccia, R.D. (2004). Can fish suffer? Perspectives on sentience, pain, fear and stress. Applied Animal Behaviour Science, 86, 225-250. 
Csanyi, V. and Doka, A. (1993). Learning interactions between prey and predator fish. Marine Behaviour and Physiology 23, 63-78.

Dawkins, M. S. (2012). Why animals matter. Animal consciousness, animal welfare, and human well-being. Oxford, U.K.: Oxford University Press.

Ehrensing, R.H., Michell, G.F. and Kastin, A.J. (1982). Similar antagonism of morphine analgesia by MIF-1 and naloxone in Carassius auratus. Pharmacology, Biochemistry and Behaviour 17, 757-761.

Iggo, A. (1984). Pain in Animals. Universities Federation for Animal Welfare: Potters Bar, Hertfordshire, UK.

Key, B. (2016). Why fish do not feel pain. Animal Sentience 2016.003.

Muto, A., Ohkura, M., Abe, G., Nakai, J., and Kawakami, K. (2013). Real-time visualization of neuronal activity during perception. Current Biology, 23, 307-311.

Odling-Smee, L. and Braithwaite V.A. (2003). The role of learning in fish orientation. Fish and Fisheries, 4, 235-246.

Pepperberg, I. M., and Hartsfield, L. A. (2014). Can grey parrots (Psittacus erithacus) succeed on a "complex" foraging task failed by nonhuman primates (Pan troglodytes, Pongo abelii, Sapajus apella) but solved by wrasse fish (Labroides dimidiatus)? Journal of Comparative Psychology, 128, 298.

Portavella, M., Torres, B. and Salas, C. (2004). Avoidance response in goldfish: Emotional and temporal involvement of medial and lateral telencephalic pallium. Journal of Neuroscience, 24, 2342-2335.

Reese, E.S. (1989). Orientation behaviour of butterfly fishes (family Chaetodontidae) on coral reefs - spatial learning of route specific landmarks and cognitive maps. Environmental Biology of Fishes, 25, 79-86.

Rodriguez, F., Duran, E., Vargas, J.P., Torres, B. and Salas, C. (1994). Performance of goldfish trained in allocentric and egocentric maze procedures suggests the presence of a cognitive mapping system in fishes. Animal Learning and Behaviour, 22, 409-420.

Rodriguez-Moldes, I., Manso, M.J., Becerra, M., Molist, P. and Anadon, R. (1993). Distribution of substance P-like immunoreactivity in the brain of the elasmobranch Scyliorhinus canicula. Journal of Comparative Neurology, 333, 228-244.

Salwiczek L.H., Prétôt, L., Demarta L., Proctor, D., Essler, J., Pinto A.I., Wismer, S., Stoinski, T., Brosnan, S. F. and Bshary, R. (2012). Adult cleaner wrasse outperform capuchin monkeys, chimpanzees and orang-utans in a complex foraging task derived from cleaner - client reef fish cooperation. PLoS ONE 7: e49068. doi:10.1371/journal.pone.0049068. 
Sneddon, L.U. (2002). Anatomical and electrophysiological analysis of the trigeminal nerve in a teleost fish, Oncorhynchus mykiss. Neuroscience Letters, 319, 167-171.

Sneddon, L.U., Braithwaite, V.A. and Gentle, M.J. (2003a). Do fish have nociceptors? Evidence for the evolution of a vertebrate sensory system. Proceedings of the Royal Society of London B, 270, 1115-1121.

Sneddon, L.U., Braithwaite, V.A. and Gentle, M.J. (2003b). Novel object test: examining nociception and fear in the rainbow trout. Journal of Pain, 4, 431-440.

Sneddon, L.U., Elwood, R.W., Adamo, S.A. and Leach, M.C. (2014). Defining and assessing animal pain. Animal Behaviour, 97, 201-212.

Wall, P.D. (1992). Defining "pain in animals." In C. E. Short \& A. van Poznak (Eds.), Animal pain (pp. 63-79). Churchill Livingstone: New York.

Yue, S., Moccia, R.D. and Duncan, I.J.H. (2004). Investigating fear in domestic rainbow trout, Oncorhynchus mykiss, using an avoidance learning task. Applied Animal Behaviour Science, 87, 343-354.

Zaccone, G., Fasula, S. and Ainis, L. (1994). Distribution patterns of the paraneuronal endocrine cells in the skin, gills and the airways of fishes determined by immunohistochemical and histological methods. Histochemistry Journal, 26, 609-629. 